\title{
PENGARUH SISTEM KEMITRAAN INTI-PLASMA TERHADAP JAMINAN PASAR, KUALITAS BAGLOG JAMUR TIRAM PUTIH DAN KEPUASAN PETANI DI CV. ASA AGRO CORPORATION KECAMATAN CUGENANG KABUPATEN CIANJUR
}

\author{
Oleh : \\ Adang Suryana*) \\ Ginia Sri Rizqi**)
}

\begin{abstract}
Abstrak
Jamur tiram putih adalah salah satu sayuran bergizi yang telah dibudidayakan dan memiliki kandungan nutrisi yang lebih tinggi dibandingkan dengan jenis jamur lainnya. CV. Asa Agro Corporation produk jamur tiram ini dan perusahaan ini telah menciptakan sistem kemitraan inti plasma yang berlokasi di Kecamatan Cugenang, Kabupaten Cianjur. Berdasarkan peraturan kemitraan, sebagaimana diatur dalam Peraturan Pemerintah Nomor 44 Tahun 1997: "kemitraan inti-plasma adalah kerjasama antara usaha kecil dengan menunjukkan prinsip-prinsip saling membutuhkan, saling menguatkan dan saling menguntungkan". Tujuan dari penelitian ini adalah untuk mengetahui Pengaruh Sistem Mitra Usaha terhadap Jaminan Pasar, dan Pengaruh Sistem Mitra Usaha terhadap Kepuasan Petani Plasma, dan Pengaruh Sistem Mitra Usaha terhadap Kualitas Jamur Tiram Baglog, dan Pengaruh Sistem Mitra Usaha Terhadap Kepuasan Petani Plasma Melalui jaminan pasar, seiring dengan Pengaruh Sistem Mitra Usaha terhadap Kepuasan Petani Plasma Melalui Kualitas Baglog Jamur Tiram. Penelitian ini menerapkan metode survei menggunakan kuesioner dan dokumentasi. Populasi dan sampel yang digunakan dalam penelitian ini sebanyak 60 responden, mereka semua yang bergabung dengan kemitraan. Penelitian ini menggunakan Structural Equation Models (SEM) untuk analisis data. Hasil penelitian ini menunjukkan bahwa sistem kemitraan inti-plasma memiliki pengaruh yang signifikan pada jaminan pasar, dan sistem Kemitraan inti-plasma memiliki pengaruh yang signifikan pada kepuasan petani plasma, dan sistem kemitraan inti-plasma memiliki pengaruh yang signifikan pada kualitas baglog jamur tiram dan tidak memiliki pengaruh langsung dari sistem kemitraan plasma inti pada kepuasan petani plasma melalui jaminan pasar tidak signifikan dan sistem kemitraan inti-plasma memiliki pengaruh langsung pada kepuasan petani plasma melalui kualitas baglog jamur tiram signifikan.
\end{abstract}

Kata Kunci : Sistem Kemitraan Inti-plasma, Jaminan Pasar, Kualitas Baglog, dan Kepuasan petani.

\begin{abstract}
White oyster mushroom is one of the nutritious vegetables that have been cultivated and it has also bigher nutrient content compared with other types of mushrooms. CV. Asa Agro Corporation produces this oyster mushroom and this company had created a plasma core partnership system located in Cugenang SubDistrict, Cianjur Regency. Based on the regulation on partnership as it is mentioned in Government Regulation No. 44 of 1997: "core-plasma partnership is cooperation between small businesses by showing the principle of mutual need, mutual strengthening and mutual benefit". The purpose of this study is to know the
\end{abstract}


influence of The Business Partner System on market assurance, and the Influence of Business Partner Systems on Plasma Farmer Satisfaction, and the Influence of Business Partner Systems on The Quality of Baglog Oyster Mushrooms, and the Influence of Bussiness Partner System on Plasma Farmer Statisfaction Through market assurance, along with the Influence of Business Partner Systems on Plasma Farmer Satisfaction Through The Quality of Oyster Mushroom Baglog. This study applied survey method using questionnaire and documentation. The population and samples used in this study as many as 60 respondents, those all who joined the partnership. This study used Structural Equation Models (SEM) for data analysis. The results of this study show that the core-plasma partnership system has a significant influence on market assurance, and the core-plasma Partnership system has a significant influence on plasma farmer satisfaction, and the core-plasma partnership system has a significant influence on the quality of oyster mushroom baglog and has no direct influence of the core-plasma partnership system on plasma farmer satisfaction through market assurance is insignificant and the core-plasma partnership system has a direct influence on plasma farmer satisfaction through the quality of oyster mushroom baglog is significant.

Keywords : Core-Plasma Partnership System, Market Assurance, Baglog Quality and Farmer Satisfaction.

*) Dosen Fakultas Sains Terapan UNSUR.

**) Alumni Fakultas Sains Terapan UNSUR. 


\section{PENDAHULUAN}

Indonesia merupakan negara yang memiliki potensi cukup besar untuk mengembangkan produk-produk pangan dan hortikultura (Maulidina,dkk 2015). Komoditas tanaman hortikultura di Indonesia memiliki beragam jenis dan dapat dibagi menjadi empat kelompok besar, yaitu tanaman buah-buahan, tanaman sayuran dan tanaman hias. Jamur tiram merupakan salah satu jenis sayuran sehat yang sudah banyak dikenal dan dikonsumsi dikalangan masyarakat dikarenakan jamur tiram putih memiliki kandungan protein tinggi, kandungan lemak yang cukup rendah, serta kandungan karbohidrat dibandingkan dengan jenis jamur tiram yang lain dapat dilihat pada tabel 1 dibawah ini :

Tabel 1. Kandungan Gizi Jamur Konsumsi Di Indonesia

\begin{tabular}{lccc}
\hline \multicolumn{1}{c}{ Jenis Jamur } & Protein & Lemak & Karbohidrat \\
\hline Jamur Tiram & 27 & 1.6 & 58 \\
Jamur Kuping & 8.4 & 0.5 & 82.8 \\
Jamur Shiitake & 17.5 & 4.9 & 78 \\
Jamur Kancing & 23.9 & 1.7 & 62.5 \\
Jamur Merang & 25.9 & 0.3 & 4 \\
\hline
\end{tabular}

Sumber : Agromedia, 2018.

Berdasarkan Badan Pusat Statistik (BPS) dikutip oleh Andriani, 2019 semakin banyaknya permintaan akan produksi jamur di Indonesia pada tahun 2016-2018 dapat dilihat pada tabel 2 dibawah ini :

Tabel 2. Produksi Jamur Tiram Putih di Indonesia 2016-2018

\begin{tabular}{|c|c|}
\hline Tahun & Kg/ Tahun \\
\hline 2016 & $40.914 .331 \mathrm{Kg}$ \\
\hline 2017 & $3.701 .956 \mathrm{Kg}$ \\
\hline 2018 & $31.051 .571 \mathrm{Kg}$ \\
\hline
\end{tabular}

Sumber : Andriani,2019.

Berdasarkan tabel 2 di atas menunjjukan jumlah produksi jamur tiram putih di Indonesia mengalami peningkatan maupun penurunan, pada tahun 2017 produksi jamur tiram putih mengalami penurunan sebesar 3.701 .956 $\mathrm{kg} /$ tahun, disebabkan oleh ketersediaan bahan baku untuk media tanam dan komposisi media tanam yang kurang tepat sehingga nutrisi yang dibutuhkan jamur tidak terpenuhi dan adanya kontaminasi.

CV. Asa Agro Corporation merupakan salah satu sentral budidaya jamur tiram yang berada di kecamatan Cugenang, kabupaten Cianjur, CV. Asa Agro Corporation diresmikan menjai badan usaha pada tanggal 03 Pebruari 2003. CV. Asa adalah salah satu badan usaha yang telah menerapkan kelembagaan tani berupa kemitraan. Landasan peraturan mengenai kemitraan di Indonesia diatur oleh peraturan pemerintah No. 44 Tahun 1997 yang menyebutkan bahwa kemitraan merupakan kerjasama antara usaha kecil dengan memperlihatkan prinsip saling memerlukan, saling memperkuat dan saling menguntungkan. Kemitraan usaha adalah kerjasama usaha kecil dengan usah menengah atau dengan usaha besar dengan memperhatikan prinsip saling memerlukan, memperkuat dan saling menguntungkan (Nofilah,2019). Sistem kemitraan yang diterapkan di CV. Asa Agro Corporation yaitu pola kemiitraan inti-plasma, pola kemitraan inti-plasma merupakan pola hubungan kemitraan antara kelompok petani mitra dan perusahaan. untuk : 
1. Mengetahui pengaruh mitra usaha terhadap jaminan pasar di CV. Asa Agro Corporation.

2. Mengetahui pengaruh mitra usaha terhadap kepuasan petani plasma di CV. Asa Agro Corporation.

3. Mengetahui pengaruh mitra usaha terhadap kualitas baglog jamur tiram putih di CV. Asa Agro Corporation.

4. Mengetahui pengaruh sistem mitra usaha terhadap kepuasan petani plasma melalui jaminan pasar di CV. Asa Agro Corporation.

5. Mengetahui pengaruh sistem mitra terhadap kepuasan petani plasma budidaya jamur tiram melalui kualitas baglog jamur tiram putih di CV. Asa Agra Corporation.

\section{METODE PENELITIAN}

Penelitian ini ber lokasi di CV. Asa Agro Corporation Desa Benjot Kecamatan Cugenang Kabupaten Cianjur dengan pertimbangan bahwa Kecamatan Cugenang merupakan salah satu sentral produkis jamur tiram putih di Kabupaten Cianjur, dan terdapat kelembagaan tani berupa kemitraan yang mampu mencakupi petani jamur tiram putih. Penelitian ini dilaksanakan pada bulan November 2019 hingga Agustus 2020. Populasi yang digunakan dalam penelitian ini 60 anggota petani plasma (responden), maka dari itu seluruh populasi dijadikan sampel. Pada penelitian ini variabel yang dikaji yaitu : Sistem Kemitraan Inti-plasma (Mitra usaha), Jaminan pasar (Jampasar), Kualitas Baglog (Kualog) dan Kepuasan Petani Plasma (Kepuasan). Untuk indikator variabel Mitra Usaha adalah penyedia sarana produksi Baglog, adanya penyuluhan kepada petani plasma, memberikan bimbingan tehnis dalam pembuatan media Baglog dan budidaya jamur tiram dan adanya bimbingan non tehnis dalam promosi atau pemasaran jamur tiram. Untuk indikator variabel Jampasar adalah perusahaan membeli hasil panen jamur, petani mendapatkan harga yang pantas dan perusahaan menanggung biaya FOB (Franco Of Buyer). Untuk indikator variabel Kualog adalah hasil panen yang bagus, jumlah panen per baglog sesuai harapan, warna jamur tiram putih bersih serta memiliki daging yang tebal, dan frekuensi panen tiap Baglog lebih dari 3 kali panen. Untuk indikator variabel Kepuasan adalah suplai baglog tepat waktu, petani memiliki kompetensi dalam budidaya jamur tiram, petani akan mempertahankan kerjasama dengan $\mathrm{CV}$. Asa Agro Corporation, petani memperoleh penghasilan tetap dan kontinyu, petani mendapatkan keuntungan setelah menjalin kemitraan dan mengajak petani jamur tiram lain untuk bergabung dalam kemitraan. 
Tabel 3. Operasional Variabel.

\begin{tabular}{|c|c|c|c|}
\hline Variabel & Konsep Variabel & Indikator & Skala \\
\hline $\begin{array}{c}\text { Sistem } \\
\text { Mitra } \\
\text { Usaha } \\
\text { (X1) }\end{array}$ & $\begin{array}{lrr}\text { Kemitraan yaitu } & \text { kerjasama } \\
\text { antara petani dan } & \text { perusahaan } \\
\text { dimana perusahaan memiliki } & \text { untuk } \\
\text { tanggung jawab r } & \text { petani dalam } \\
\text { membantu paktor produksi, } \\
\text { penyediaan fan } \\
\text { penjualan hasil produksi, serta } \\
\text { membina petani dari sisi teknis } \\
\text { maupun manajerial menurut } \\
\text { (Erviana, 2016). }\end{array}$ & $\begin{array}{l}\text { 1) Penyediaan sarana produksi } \\
\text { berupa baglog } \\
\text { 2) Adanya penyuluhan yang } \\
\text { diberikan oleh perusahaan } \\
\text { kepada petani plasma } \\
\text { 3) Adanya bimbingan tehnis } \\
\text { dalam pembuatan media dan } \\
\text { budidaya jamur tiram } \\
\text { 4) Adanya bimbingan non tehnis } \\
\text { dalam promosi jamur tiram }\end{array}$ & $\begin{array}{l}\text { Likert (1-5) } \\
\text { Jenis data } \\
\text { yang } \\
\text { diperoleh } \\
\text { yaitu ordinal }\end{array}$ \\
\hline $\begin{array}{c}\text { Jaminan } \\
\text { Pasar } \\
\text { (Y1) }\end{array}$ & $\begin{array}{l}\text { Jaminan adalah sesuatu yang } \\
\text { diberikan kepada petani untuk } \\
\text { menimbulkan keyakinan bahwa } \\
\text { perusahaan akan memenuhi } \\
\text { kewajiban yang akan dapat } \\
\text { dinilai dengan jumlah harga } \\
\text { yang diperoleh dan timbul dari } \\
\text { suatu perikatan (Hadisoeprapto, } \\
\text { 2004). }\end{array}$ & $\begin{array}{l}\text { 1) Perusahaan membeli hasil } \\
\text { panen jamur petani. } \\
\text { 2) Petani mendapatkan harga } \\
\text { yang pantas. } \\
\text { 3) Perusahaan menanggung biaya } \\
\text { FOB (franco of buyer), }\end{array}$ & $\begin{array}{l}\text { Likert (1-5) } \\
\text { Jenis data } \\
\text { yang } \\
\text { diperoleh } \\
\text { yaitu ordinal }\end{array}$ \\
\hline $\begin{array}{c}\text { Kualitas } \\
\text { Baglog } \\
\text { Jamur } \\
\text { Tiram } \\
\text { (Y2) }\end{array}$ & $\begin{array}{l}\text { Kualitas merupakan } \\
\text { kondisi dinamis }\end{array} \begin{array}{r}\text { yang } \\
\text { berhubungan dengan } \\
\text { produk, } \\
\text { jasa, manusia, proses, } \\
\text { lingkungan yang memenuhi } \\
\text { melebihi harapan (Tjiptono } \\
\text { 2008) }\end{array}$ & $\begin{array}{l}\text { 1) Hasil panen bagus. } \\
\text { 2) Jumlah panen per baglog } \\
\text { sesuai harapan. } \\
\text { 3) Warna jamur tiram putih } \\
\text { bersih dan Daging tebal. } \\
\text { 4) Frekuensi panen tiap baglog } \\
\text { lebih dari } 3 \text { kali. }\end{array}$ & $\begin{array}{l}\text { Likert (1-5) } \\
\text { Jenis data } \\
\text { yang } \\
\text { diperoleh } \\
\text { yaitu ordinal }\end{array}$ \\
\hline $\begin{array}{c}\text { Kepuasan } \\
\text { Petani } \\
\text { Plasma } \\
\text { (Y3) }\end{array}$ & $\begin{array}{l}\text { Menurut Kotler dan Keller } \\
\text { (2013) menyatakan kepuasan } \\
\text { (satisfaction) adalah perasaan } \\
\text { senang atau kecewa pada diri } \\
\text { seseorang yang timbul karena } \\
\text { membandingkan kinerja yang } \\
\text { dipersepsikan produk atau hasil } \\
\text { terhadap ekspektasi mereka } \\
\text { Jika performance gagal memenuhi } \\
\text { harapan, maka pelanggan tidak } \\
\text { akan puas, jika performance sesuai } \\
\text { dengan harapan, maka } \\
\text { pelanggan akan merasa sangat } \\
\text { puas. }\end{array}$ & $\begin{array}{l}\text { 1) Suplai baglog tepat waktu. } \\
\text { 2) Petani mempunyai kopetensi } \\
\text { dalam budidaya jamur tiram } \\
\text { 3) Petani akan mempertahankan } \\
\text { kerjasama dengan CV. Asa } \\
\text { Agro Corporation } \\
\text { 4) Petani memperoleh } \\
\text { penghasilan tetap dan } \\
\text { kontinyu. } \\
\text { 5) Petani akan mendapatkan } \\
\text { keuntungan setelah menjalin } \\
\text { kemitraan } \\
\text { 6) Mengajak petani lain } \\
\text { bergabung }\end{array}$ & $\begin{array}{l}\text { Likert (1-5) } \\
\text { Jenis data } \\
\text { yang } \\
\text { diperoleh } \\
\text { yaitu ordinal }\end{array}$ \\
\hline
\end{tabular}

Adapun metode analisis dalam penelitian ini adalah metode analisis deskriptif kuantitatif. Yaitu analisis yang berkaitan dengan angka, frekuensi serta presentase. Dengan cara pengujian uji validitas dengan menggunakan loading faktor, reliabilitas atau nyata, dan uji analisis Structural Equation Modeling (SEM) digunakan untuk mengukur model pengukuran (Measurement Model), model struktural (Structural Model) dan Goodness Fit Model.

\section{HASIL DAN PEMBAHASAN}

\section{Gambaran Umum Lokasi Penelitian}

Secara geografis Desa Benjot terletak di Selatan Kecamatan Cugenang Kabupaten Cianjur, di antara "060 50 ' 039 " Lintang Selatan dan 1070 03’ 542” Bujur Timur. Wilayah Desa Benjot memiliki luas 
kurang lebih 215,735 Ha (Sumber : Peta Zona PBB Tahun 2004), Desa Benjot terdiri dari 6 Rukun Warga (RW) yang membawahin 22 Rukun Tetangga (RT). Secara administratif Desa Benjot berbatasan dengan :

1) Sebelah Utara berbatasan dengan Desa Gasol

2) Sebelah Selatan berbatasan dengan Desa Cibulakan

3) Sebelah Timur berbatasan dengan Desa Cibulakan

4) Sebelah Barat berbatasan dengan Desa Talaga/ Sarampad

\section{Karakteristik Responden}

Dari hasil kuisioner yang dilakukan terhadap 60 orang responden. Maka dapat diketahui karakteristik responden petani jamur yang bermitra dengan CV. Asa Agro Corporation, diantaranya : jenis kelamin, pendidikan, usia, pendapatan perbulan dan program kemitraan. Jenis kelamin responden sebagian besar adalah laki-laki yaitu sebanyak 42orang $(70 \%)$, sedangkan responden perempuan yaitu sebanyak 18 orang $(30 \%)$. Pendidikan responden sebagian besar adalah SMA yaitu sebanyak 31 orang $(52 \%)$, SMP yaitu sebanyak 15 orang (25\%), Perguruan Tinggi yaitu sebanyak 11 orang $(18 \%)$ dan SD yaitu sebanyak 3 orang (5\%). Usia responden sebagian besar adalah 35-50 tahun yaitu sebanyak 41 orang $(68 \%), 25$ 35 tahun yaitu sebanyak 13orang $(22 \%)$, 18-25 tahun yaitu sebanyak 5 orang $(8 \%)$ dan kurang dari 18 tahun yaitu sebanyak 1 orang $(2 \%)$. Pendapatan perbulan responden sebagian besar adalah 3-5 juta yaitu sebanyak (42\%), 2-3 juta yaitu sebanyak (30\%), kurang dari 1 juta (18\%) dan 1-2 juta sebanyak (10\%). Program kemitraan sebagian besar adalah kurang dari 6 tahun yaitu sebanyak 32 orang (53\%), 6-9 tahun yaitu sebanyak 13 orang (22\%), 9-12 tahun yaitu sebanyak 13 orang $(22 \%)$ dan $12-15$ tahun yaitu 2 orang $(3 \%)$.

\section{Analisis Faktor}

Adapun hasil output uji validitas dan reliabilitas yang dilakukan pada sistem kemitraan inti plasma (mitra usaha) (X1) adalah sebagai berikut :

Tabel 4.Uji Validitas Mitra Usaha.

\begin{tabular}{ccc}
\hline & Variabel Mitra Usaha & \\
\hline Indikator & Nilai Validitas & Keterangan \\
\hline MU1 & 0.778 & Validitas Tinggi \\
MU2 & 0.873 & Validitas Sangat Tinggi \\
MU3 & 0.938 & Validitas Sangat Tinggi \\
MU4 & 0.794 & Validitas Tinggi \\
\hline
\end{tabular}

Exctraction Method: Principal Component Analysis.

Sumber: Data Primer Hasil Dari IBM SPSS Vs 21 (2020).

Tabel 5. Uji Reliabilitas Variabel Mitra Usaha.

\begin{tabular}{ccc}
\hline \multicolumn{3}{c}{ Variabel Mitra Usaha } \\
\hline Cronbach's Alpha & Cronbach's Alpha Based on Standardized Items & N of Items \\
\hline 0.864 & 0.864 & 4 \\
\hline
\end{tabular}

Sumber: Data Primer Hasil Dari IBM SPSS Vs 21 (2020).

Dapat dilihat tabel di atas menunjukkan bahwa Nilai validitas yang terdapat pada variabel Mitra usaha (MU) memperoleh hasil nilai di atas 0.70 dengan nilai Cronbach Alpha 0.864 dianggap nilai variabel mitra usaha valid karena nilai validitas $>0.70$. 
Uji Validitas dan Reliabilitas Variabel Jaminan Pasar (Y1)

Tabel 6. Uji Validitas Variabel Jaminan Pasar.

\begin{tabular}{ccc}
\hline & Variabel Jaminan Pasar \\
\hline Indikator & Nilai Validitas & Keterangan \\
\hline JP1 & 0.893 & Validitas Sangat Tinggi \\
JP2 & 0.769 & Validitas Tinggi \\
JP3 & 0.884 & Validitas Sangat Tinggi \\
\hline
\end{tabular}

Exctraction Method: Principal Component Analysis

Sumber: Data Primer Hasil Dari IBM SPSS Vs 21 (2020)

Tabel 7. Uji Reliabilitas Variabel Jaminan Pasar

\begin{tabular}{ccc}
\hline \multicolumn{3}{c}{ Variabel Jaminan Pasar } \\
\hline Cronbach's Alpha & Cronbach's Alpha Based on Standardized Items & N of Items \\
\hline 0.804 & 0.804 & 3 \\
\hline Sumber : Data Primer Hasil Dari IBM SPSS Vs 21 (2020).
\end{tabular}

Sumber : Data Primer Hasil Dari IBM SPSS Vs 21 (2020).

Dapat dilihat pada tabel di atas bahwa nilai validitas pada variabel Jaminan Pasar (JP) memperoleh hasil nilai di atas 0.70 dengan nilai Cronbach Alpha
0.804 diatas $>0.70$ yang dianggap tinggi, karena nilai pada setiap indikator yang diperoleh bernilai valid.

\section{Uji Validitas Dan Reliabilitas Variabel Kualitas Baglog (Y2)}

Tabel 8. Uji Validitas Variabel Kualitas Log.

\begin{tabular}{ccc}
\hline & Variabel Kualitas Log & \\
\hline Indikator & Nilai Validitas & Keterangan \\
\hline KL1 & 0.906 & Validitas Sangat Tinggi \\
KL2 & 0.893 & Validitas Sangat Tinggi \\
KL3 & 0.803 & Validitas Tinggi \\
KL4 & & Tidak Valid \\
\hline
\end{tabular}

Exctraction Method: Principal Component Analysis

Sumber: Data Primer Hasil Dari IBM SPSS Vs 21 (2020).

Tabel 8. Uji Reliabilitas Variabel Kualitas Log.

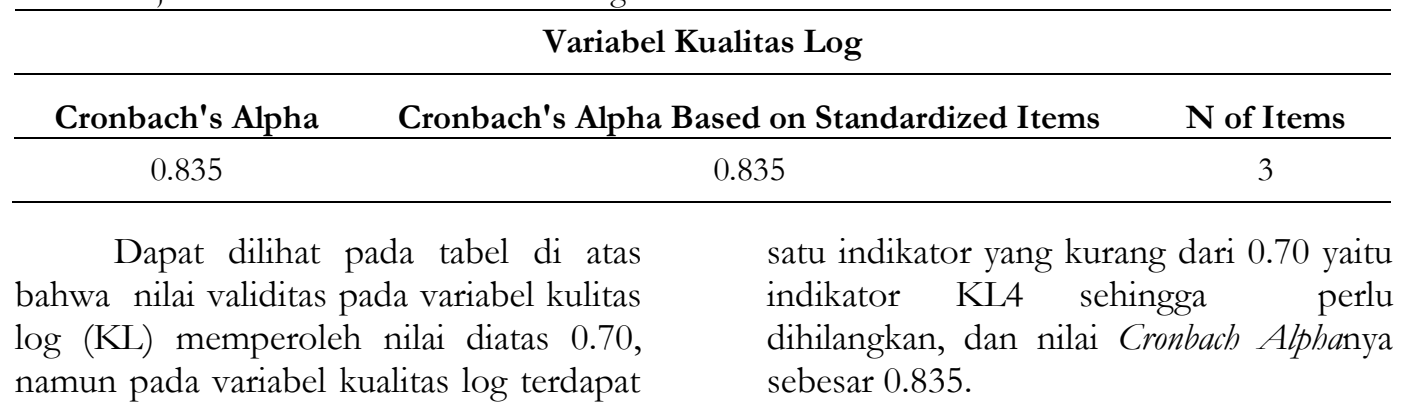


Uji Validitas dan Reliabilitas Variabel Kepuasan Petani (Y3)

Tabel 9. Uji Validitas Variabel Kepuasan Petani.

\begin{tabular}{ccc}
\hline & Variabel Kepuasan Petani \\
\hline Indikator & Nilai Validitas & Keterangan \\
\hline KP1 & 0.770 & Validitas Tinggi \\
KP2 & 0.802 & Validitas Tinggi \\
KP3 & 0.763 & Validitas Tinggi \\
KP5 & 0.766 & Validitas Tinggi \\
\hline
\end{tabular}

Exctraction Method: Principal Component Analysis

Sumber: Data Primer Hasil Dari IBM SPSS Vs 21 (2020).

Tabel 10. Uji Reliabilitas Variabel Kepuasan Petani

Variabel Kepuasan Petani

\begin{tabular}{ccc}
\hline Cronbach's Alpha & Cronbach's Alpha Based on Standardized Items & N of Items \\
\hline 0.773 & 0.773 & 4
\end{tabular}

Sumber: Data Primer Hasil Dari IBM SPSS Vs 21 (2020).

Dapat dilihat pada tabel di atas bahwa nilai validitas pada variabel kepuasan petani (KP) memperoleh nilai di atas 0.70 namun terdapat dua indikator yag kurang dari 0.70 yaitu pada indikator KP4 dan KP6 perlu dihilangkan atau dihapus, dan nilai cronbach alpha yang diperoleh sebesar 0.773 .

\section{Model Pengukuran (Measurement Model)}

Tabel 11. Means, Standard Deviation Dan Loading Factor Dari Variabel Mitra Usaha.

\begin{tabular}{lrrr}
\hline \multicolumn{1}{c}{ Indikator } & \multicolumn{1}{c}{ Mean } & Standar Deviation & Loading Faktor $(\boldsymbol{\lambda})$ \\
\hline MU1 & 4.2833 & 0.73857 & 0.66 \\
MU2 & 3.9000 & 0.96901 & 0.81 \\
MU3 & 3.7333 & 1.08716 & 0.99 \\
MU4 & 3.6500 & 1.10200 & 0.72
\end{tabular}

Sumber: Data Primer dari IBM SPSS vs 21 dan AMOS Graphics vs 24 (2020).

Tabel di atas menunjukkan bahwa variabel Mitra usaha mempunyai nilai Loading Faktor $>0.7$, namun pada indikator MU1, namun terdapat satu indikator yang mempunyai nilai Loading faktor hampir mendekati 0.70 .

Tabel 12. Means, Standard Deviation Dan Loading Factor Dari Variabel Jaminan Pasar.

\begin{tabular}{lrrr}
\hline \multicolumn{1}{c}{ Indikator } & \multicolumn{1}{c}{ Mean } & Standar Deviation & Loading Faktor $(\lambda)$ \\
\hline JP1 & 4.4333 & 0.87074 & 0.88 \\
JP2 & 4.0000 & 0.93881 & 0.59 \\
JP3 & 4.1000 & 1.02014 & 0.84 \\
\hline
\end{tabular}

Sumber: Data Primer Dari IBM SPSS vs 21 dan AMOS Grapchis vs 24 (2020).

Tabel di atas menunjukkan bahwa variabel Jaminan pasar mempunyai nilai Loading Faktor $(\lambda)>0.7$, namun terdapat satu indikator loading faktor yang kurang dari 0.70 . 
Tabel 13. Means, Standard Deviation Dan Loading Factor Dari Variabel Kualitas Log (KL).

\begin{tabular}{lccc}
\hline \multicolumn{1}{c}{ Indikator } & Mean & Standar Deviation & Loading Faktor $(\boldsymbol{\lambda})$ \\
\hline KL1 & 4.1833 & 0.79173 & 0.86 \\
KL2 & 3.9500 & 0.83209 & 0.87 \\
KL3 & 4.3500 & 0.63313 & 0.67 \\
KL4 & 4.3500 & 0.77733 & 0.48 \\
\hline \multicolumn{2}{l}{ Sumber: Data Primer Dari IBM SPSS vs 21 dan AMOS Grapchis vs 24 (2020). }
\end{tabular}

Tabel di atas menunjukkan bahwa variabel Kualitas log (Kualog) mempunyai nilai Loading Faktor $(\lambda)>0.7$, namun terdapat satu indikator KL4 kurang dari 0.70 .

Tabel 14. Means, Standard Deviation Dan Loading Factor Dari Variabel Kepuasan Petani Plasma.

\begin{tabular}{lccc}
\hline \multicolumn{1}{c}{ Indikator } & Mean & Standar Deviation & Loading Faktor $(\boldsymbol{\lambda})$ \\
\hline KP1 & 4.2000 & 0.70830 & 0.70 \\
KP2 & 4.1167 & 0.73857 & 0.76 \\
KP3 & 4.4833 & 0.53652 & 0.64 \\
KP5 & 4.1333 & 0.74712 & 0.63
\end{tabular}

Sumber: Data Primer Dari IBM SPSS vs 21 dan AMOS Grapchis vs 24 (2020).

Tabel di atas menunjukkan bahwa variabel Kepuasan petani plasma mempunyai nilai Loading Faktor $(\lambda)>$

\section{Model Struktural (Structural Model)}

Tabel 15. Standardized Regression Weights: (Group number 1 - Default model awal).

\begin{tabular}{llll}
\hline & & & Estimate \\
\hline Kualitas & $<---$ & MitraUsaha & 0.306 \\
Kepuasan & $<---$ & MitraUsaha & 0.325 \\
Kepuasan & $<---$ & Kualitas & 0.840 \\
Kepuasan & $<---$ & MitraUsaha & 0.273 \\
kp1 & $<---$ & JamPasar & 0.199 \\
kp2 & $<---$ & Kepuasan & 0.521 \\
kp3 & $<---$ & Kepuasan & 0.547 \\
kp5 & $<---$ & Kepuasan & 0.633 \\
k14 & $<---$ & Kepuasan & 0.862 \\
k13 & $<---$ & Kualitas & 0.502 \\
k12 & $<---$ & Kualitas & 0.716 \\
k11 & $<---$ & Kualitas & 0.805 \\
Mu1 & $<---$ & Kualitas & 0.878 \\
mu2 & $<---$ & MitraUsaha & 0.685 \\
mu3 & $<---$ & MitraUsaha & 0.845 \\
mu4 & $<---$ & MitraUsaha & 0.931 \\
jp3 & $<---$ & MitraUsaha & 0.741 \\
jp2 & $<---$ & JamPasar & 0.951 \\
jp1 & $<---$ & JamPasar & 0.542 \\
Sumber & $<--$ & JamPasar & 0.769 \\
\hline
\end{tabular}

Sumber : Data Primer diolah melalui AMOS Graphics vs 24 (2020).

0.7 , namun terdapat 2 indikator yang memiliki nilai loading faktor kurang dari 0.70 . 
Tabel di atas menunjjukan nilai estimasi dari standardized regresi. Dari tabel tersebut dapat dilihat bahwa nilai estimasi keseluruhan parameter tidak memiliki nilai yang lebih dari satu dan tidak ada nilai estimasi yang negatif, maka dari itu spesifikasi model dalam penelitian ini sudah baik karena tidak terjadi Heywood cases.

\section{Goodness Fit Model Awal dan} Alternatif

Pada model alternatif, nilai GFI melebihi 0.90 yaitu 0.996 yang dinyatakan ukuran fit modelnya sangat baik. Dari perbandingan kedua model itu, maka dapat diketahui bahwa model akhir memiliki hasil yang baik dibandingkan dengan model awal, perbandingan antara kedua model dapat dilihat pada tabel 16 di bawah ini :

Tabel 16. Goodness Fit Model Awal dan Alternatif.

\begin{tabular}{lccc}
\hline Goodness Fit Model & Model Awal & Model Alternatif & Keterangan \\
\hline Chi Square & 244.883 & 0.439 & Menurun, Lebih Baik \\
Df & 85 & 1 & \\
Cmin/Df & 2.881 & 0.439 & Menurun, Lebih Baik \\
RMSEA & 0.179 & 0.000 & Menurun, Lebih Baik \\
GFI & 0.684 & 0.996 & Meningkat, Lebih Baik \\
AIC & 314.883 & 18.439 & Menurun, Lebih Baik \\
CAIC & 432.185 & 46.288 & Menurun, Lebih Baik \\
PCFI & 0.582 & 0.167 & Menurun, Lebih Baik \\
RMR & 0.098 & 0.013 & Menurun, Lebih Baik \\
ECVI & 5.337 & 0.313 & Menurun, Lebih Baik \\
CFI & 0.719 & 1.000 & Meningkat, Lebih Baik \\
\hline
\end{tabular}

Sumber: Data Primer hasil dari AMOS Graphics (2020).

\section{Goodness Fit Model Keseluruhan}

Hasil dari goodness fit model keseluruhan yang dihasilkan dari sembilan fit model di atas, bahwa ke sembilan model dinyatakan fit sesuai dengan kriteria goodness fit model, dapat dilihat pada tabel 17 di bawah ini:

Tabel 17. Goodness Fit Model Keseluruhan.

\begin{tabular}{|c|c|c|c|}
\hline FIT INDEKS & AMBANG BATAS & NILAI & KETERANGAN \\
\hline Chi-square & $\begin{array}{c}\text { Kecil } \\
\mathrm{P}=0.05\end{array}$ & $\begin{array}{l}0.439 \\
0.508\end{array}$ & Baik \\
\hline CMIN/DF & $<2$ & 0.439 & Baik \\
\hline GFI & $>0.95$ & 0.996 & Baik \\
\hline RMSEA & $<0.08$ & 0.000 & Baik \\
\hline AIC dan & $\begin{array}{l}\mathrm{DF} \\
\mathrm{SM}\end{array}$ & $\begin{array}{l}18.439 \\
20.000\end{array}$ & Baik \\
\hline CAIC & $\begin{array}{l}\text { DF } \\
\text { SM }\end{array}$ & $\begin{array}{l}46.288 \\
50.943\end{array}$ & Baik \\
\hline PCFI & $>0.6$ & 0.167 & Baik \\
\hline RMR & $<0.05$ & 0.013 & Baik \\
\hline CFI & $>0.90$ & 1.000 & Baik \\
\hline ECVI & $\begin{array}{c}\mathrm{DM} \\
\mathrm{SM}\end{array}$ & $\begin{array}{l}0.313 \\
0.339\end{array}$ & Baik \\
\hline
\end{tabular}

Sumber: Data Primer hasil AMOS Graphics vs 24 (2020). 


\section{KESIMPULAN}

Berdasarkan hasil penelitian dan pembahasan yang dilakukan serta hasil uji analisi jalur maupun analisis SEM (Structural Equation Modelling) untuk mengetahui faktor yang mempengaruhi secara langsung maupun secara tidak langsung terhadap jampasar, kualog jamur tiram serta kepuasan petani plasma di CV. Asa Agro Corporation Kecamatan Cugenang, maka dapat ditarik kesimpulan sebagai berikut :

1. Terdapat pengaruh langsung yang signifikan antara variabel mitra usaha terhadap variabel jaminan pasar.

2. Terdapat pengaruh langsung yang signifikan antara variabel mitra usaha terhadap kepuasan petani plasma.

3. Terdapat pengaruh langsung yang signifikan antara variabel mitra usaha terhadap kualitas Baglog.

4. Pengaruh tidak langsung variabel mitra usaha terhadap kepuasan petani plasma melalui jaminan pasar adalah tidak signifikan.

5. Pengaruh tidak langsung variabel mitra usaha terhadap kepuasan petani plasma melalui kualitas Baglog adalah signifikan.

\section{DAFTAR PUSTAKA}

Agromedia. Keistimewaan Nutrisi Dan Kandungan Obat Dalam Jamur https://agromedia.net/keistimewaa n-nutrisi-dan-kandungan-obatdalam-jamur-2/ Diakses Pada, 28 Maret 2020

Chazali, S., dan P Pratiwi. 2010. Usaha Jamur Tiram Skala Rumah Tangga. Jakarta: Swadaya.
Erviana, V. 2016. Pengaruh Kemitraan Terhadap Pendapatan Dan Efisiensi Produksi Usahatani Jamur Tiram Putih Pola Kemitraan Dan Non-Kemitraan Di Kecamatan Ciawi. Skripsi. Bogor.

Hadisoeprapto, H. 2004. Pokok-Pokok Hukum Perikatan dan Hukum Jaminan, Liberty. Yogyakarta.

Kotler, Philip, dan KL Keller. 2013. Manajemen Pemasaran, Jilid 2, Edisi 13, Erlangga, Jakarta.

Maulidina, dkk 2015. Pengaruh Umur Bibit Dan Komposisi Media Tana Terhadap Pertumbuhan Dan Hasil Jamur Tiram Putih (Pleurotus ostreatus). Universitas Brawijaya. Malang.

Nofilah. 2019. Pengembangan Kemitraan Dalam Memperkuat Relasi Organisasi Di Pusat Koperasi Syirkah Syari'ah Muawwanah (Puskopssim) pwnu. Jawa Timur Surabaya.

Riadi. 2019. Jamur tiram. https://www.kajianpustaka.com/2 019/07/jamur-tiram.html diakses, pada 16 Januari 2020.

Rodjak, Abdul. 2006. Manajemen Usahatani. Bandung: Pustaka Giratuna.

Schiffman., dan Kanuk, 2007. Perilaku Konsumen. Edisi Kedua. Jakarta: PT. Indeks Gramedia.

Sumardjo, dkk 2010. Teori Kemitraan Menurut Para Abli. https://www.hestanto.web.id/teori -pola-kemitraan-menurut-paraahli/ diakses pada 16 Januari 2020. 